\title{
Occupational Disruption and Natural Disaster: Finding a 'New Normal' in a Changed Context
}

\author{
Sima, L., Thomas, Y. \& Lowrie, D.
}

\begin{abstract}
:
Individuals affected by natural disasters can undergo critical life changes throughout the recovery process. With a forecast increase in frequency and impact of natural disasters it is important to consider the occupational recovery process that individuals experience postdisaster. This qualitative descriptive study explored the experience of occupational disruption and occupational recovery of individuals two years after Cyclone Yasi struck a small, regional town in Northern Queensland, Australia. Nine semi-structured interviews from long-term residents of the town affected by Cyclone Yasi were conducted two years after the event. Interviews were recorded, transcribed verbatim and independently coded using thematic analysis by three researchers. Five interrelated themes were identified through this research. These included: 'Recovery occupations'; 'Interruption to leisure and productive occupations'; 'Reconstruction: a second disaster'; 'Occupational liminality' and 'A new normal'. These themes point to a phased process of occupational recovery through which disaster survivors encounter numerous personal and contextual barriers, encumbering their return to re-engagement in meaningful occupational routines. The findings from this research offer insights into the support needs of both individuals and communities as they endeavour to overcome challenges associated with the recovery process.
\end{abstract}

\section{Key words:}

Natural disaster, Occupational disruption, Occupational recovery, Occupational adaptation

\section{Introduction:}

Natural disasters are a common occurrence, not only in Australia but worldwide. Natural disasters, such as cyclones, tsunamis, floods, earthquakes and bushfires, affect millions of people across the globe. A disproportionate number of natural disasters are reported in 
developing countries, especially those on the Asian continent (Guha-Sapir, Vos, \& Below, 2011). Given the expected increase in both severity and frequency of natural disasters, the development of an improved understanding of the occupational recovery process that individuals and communities experience post-disaster is important (Smith \& Scaffa, 2014) . Individuals affected by natural disasters can undergo critical life changes throughout the recovery process and experience both transient and longer-term changes across their selfcare, leisure and productivity occupations (Taylor, Jacobs, \& Marsh, 2011; Townsend \& Polatajko, 2013). Disasters can have a negative impact upon people's physical, emotional and social well-being and, in turn, have the potential to disrupt the established roles and routines of both individuals and broader communities (AOTA, 2011; Caruana, 2010; Lee, 2014).

Occupational disruption refers to a temporary interruption to an individual's occupational engagement, which can be ameliorated through re-engagement in purposeful and meaningful occupations (Whiteford, 2010). Occupational disruption differs from other similar phenomena, such as occupational deprivation and dysfunction, as it is generally a temporary state which can be alleviated (Townsend \& Polatajko, 2013; Whiteford, 2010). The occupational impact of natural disasters tends to be temporary in nature due to the fact that, although the environment and occupation may never be restored to their former state, occupational adaptation can occur to enable a resumption of functioning (Townsend \& Polatajko, 2013).

The aftermath of a natural disaster has been described as comprising immediate post-impact, recovery and reconstruction phases (AOTA, 2011). The importance of addressing the wide array of physical, cognitive, emotional and interpersonal effects of the disaster throughout each of these phases in order to promote occupational well-being, is argued, in principle, in a number of papers (AOTA, 2011; Jeong, Law, DeMatteo, Stratford, \& Kim, 2016). A practical example of this can be found in recent work by Lee (2014) who describes efforts towards the management of emotional and physical trauma in a post-earthquake situation, with the goal of prompting improved occupational performance among survivors through rehabilitation.

The role of occupational engagement as a recovery modality following disaster is also discussed in a number of papers. More than three decades ago, Rosenfeld (1982) proposed "activity intervention" as serving a crucial function in facilitating coping responses among 
disaster survivors. Similarly, in describing the difficult times following the terrorist attacks of September $11^{\text {th }} 2001, \operatorname{McC}$ coll $(2002$, p. 350) referred to occupation as acting as a "bridge to health" by nurturing hope, grounding and connection. More recently, Rushford and Thomas (2015) asserted that both rebuilding and transformation of occupations are defining characteristics of disasters and of the recovery process. They argued that re-engagement in occupation constitutes an important aspect of the post-disaster recovery process of individuals and communities. Qualitative research by Pizzi (2015), entailing analysis of written narratives from occupational therapy students who had experienced Hurricane Sandy, would seem to support this position. This research found that occupation acted as an "anchor" in supporting recovery, resilience and adaptation among participants (Pizzi, 2015, p. 7).

All of the above literature points to the notion that, although occupation is compromised in a natural disaster, it also serves a significant role in the physical, emotional and social recovery processes. With this in mind, substantial gains could be made for both individuals and communities through the enablement of occupational recovery and adaptation as part of the disaster response. The development of an in-depth understanding of the way in which individuals experience occupational disruption and subsequent occupational recovery following a natural disaster is thus critical to effective work in disaster response. To date, however, there exists no published research specifically exploring the lived experiences of occupational disruption and recovery among disaster survivors. Research focussing on the impact of the occupational losses brought on by natural disaster and the nature of the challenges that confront survivors as they attempt to resume their valued roles and routines is therefore, warranted.

This research seeks to shed light on these phenomena by exploring the occupational experiences of survivors, two years after a major cyclone that struck a small, regional Australian town on the coast of North Queensland. In doing so, the research aims to answer the following key questions:

- What is the lived experience of occupational disruption during the immediate postimpact, recovery and reconstruction phases of a natural disaster?

- In what way do the processes of occupational adaptation and recovery evolve over time? 


\section{Methodology:}

\section{Research approach}

The focus of this study was to explore the experience of occupational disruption and recovery for individuals who had lived through a natural disaster, one to two years after the event. For this reason, a qualitative descriptive research design was chosen for the study. Qualitative descriptive research is grounded in the principles of naturalistic inquiry (Sandelowski, 2010). The approach entails researchers exploring phenomena such as events and experiences and then explaining these phenomena in a way that best fits the data gathered (Colorafi \& Evans, 2016). To this end, researchers undertaking qualitative descriptive research are able to draw on a range of interpretive theories and frameworks in guiding their study design and process of analysis, provided that these approaches allow them to stay close to the surface of words and events (Colorafi \& Evans, 2016; Sandelowski, 2010).

The principal investigator is a long-term resident of the regional Australian town in which the study was undertaken and conducted this study as an insider researcher. Insider research is carried out by an individual from the same population as those being studied (Kanuha, 2000). This close connection with the community enabled greater access to networks and individuals, allowing for an insider view into the phenomena of occupational disruption and recovery (Corbin Dwyer \& Buckle, 2009).

\section{Participant recruitment and selection}

The inclusion criteria for participants in this research were as follows:

- Residency in [regional Australian town affected by cyclone].

- Long-term residency (10 years or more) in [regional Australian town].

- Aged between 25 and 65 years.

Despite the cyclone affecting a geographical area larger than the regional Australian town from which participants were recruited, only residents of this town were included. This enabled a more nuanced exploration of a variety of experiences within a cyclone-affected community. Individuals who had lived in the town for less than 10 years were not included 
differences may have been present in the meanings relating to attachment to their environment, lifestyle patterns and disruption of routines. The defined age range aimed to include adults who were of working age, excluding a transient young-adult population who may not have settled in the town permanently.

This study received ethical approval from the James Cook University Ethics Committee (approval number H4627). Awareness of the study was raised by posting adverts for the study on noticeboards and within the local newspaper. Participants were recruited purposively, initially via expressions of interest and thereafter through a process of snowball sampling. Written consent was gained prior to the commencement of each interview and then revisited verbally on interview completion. The final sample of participants included three men and six women, all of whom met the inclusion and exclusion criteria. Due to the rich nature of the data collected, nine interviews were successful in achieving data saturation. Agreement on the achievement of data saturation was made collectively by the research team at the point when no new ideas or themes were being identified from the data set.

\section{Data collection and analysis}

The Principal Researcher (first author) undertook semi-structured interviews with participants in order to allow them to openly discuss their experience of occupational disruption and recovery following the cyclone. Open-ended questions were used during the interview process, enabling individuality and variability in topics discussed between the different participants. This flexible approach was complemented by the use of an interview checklist which assisted the researcher in ensuring that key areas of research interest were discussed within each interview (please see Appendix 1 for details). Interviews ranged in length between 50 minutes and 1 hour 54 minutes with an average duration of 70 minutes. All interviews were conducted in participants' homes. This environment is thought to have a positive effect upon the data yielded in a study of this nature, through the elicitation of memories of the event and the subsequent recovery process they had experienced (Britten, 1995).

Interviews were audio-taped with the participants' consent and later transcribed verbatim. In order to maintain confidentiality, all data was de-identified directly after the interview process. All data was stored in a secure location and confidentiality was maintained at all times. Pseudonyms have been used for all participants in this paper. 
Line by line coding of data was undertaken by all three members of the research team and core themes arrived at using the four stages of thematic analysis recommended by Van Manen (1990) as a guide. A series of meetings were held between the research team to discuss coding and to agree on themes. The final themes were those which were deemed to be essential in creating a description of the phenomena being explored. Rigour within the data analysis process was promoted by having all transcripts independently coded by the three researchers. This process of 'inter-coder agreement' demonstrated broad consistency with similar outcomes being produced by all members of the research team (Creswell, 2013). Member checking was also undertaken by providing participants with copies of their transcribed interview for review. All participants indicated that the transcripts represented an authentic account of their thoughts and experiences. Transparency and reflexivity within the research process was fostered through the maintenance of a reflective diary by the principal researcher throughout the data collection and analysis processes. This record of thoughts, reflections and emerging ideas offered a foundation for in-depth discussions about the research findings between the research team.

\section{Findings:}

Narrative data from nine participants were gathered within this study. Six of the participants were female and three participants were male with ages ranging from 35 to 65 years of age. Three of the participants worked in retail which, due to its close links with tourism, is one of the prominent industries (along with fishing and tourism itself) within the regional town affected by the cyclone. Other working roles included fishing, construction, mother (and business administrator), real estate agent, and garden maintenance. One participant was a retiree. A breakdown of the demographic details of the specific study participants is included below).

\section{[PLEASE ATTACH TABLE 1 HERE]}

As stated above, five core themes were identified as being central to the occupational experiences of the individuals in the two years following the impact of the cyclone. These themes include: 'Recovery occupations', 'Interruption to leisure and productive 
occupations', 'Reconstruction: a second disaster', 'Occupational liminality' and 'A new normal'. Each of these themes is outlined below.

\section{Recovery occupations}

In the immediate post-impact and (early) recovery phases following Cyclone Yasi, the focus for all individuals related to engagement in occupations which counteracted the lifethreatening effects and devastation brought about by the event. This first theme identifies the recovery occupations that facilitated the immediate clean-up and assisted the community as a whole to begin the recovery process. Individuals engaged in recovery occupations not only to assist their own recovery but also to provide assistance to others and to support the reestablishment of the community. During this time, survivors of the disaster appeared to be occupationally thriving as they engaged in occupations surrounding recovery which were both meaningful and purposeful. These recovery occupations began immediately after the cyclone and continued for several months for many individuals.

On returning to the town after being evacuated, individuals described how they began the process of recovery. Participants reported that during this time they felt a strong sense of community connection as individuals put the needs of others above those of themselves.

"But you do all this running around because somebody needs this or somebody needs that and somebody needs something else and I need something so I will go out there and get it".

(Beth)

"You just need to get in and get it done and if anyone else needs help then help them as well. We all pitched in around here, all our neighbours. That sort of thing brings people together".

(Hugh)

"I think that was sort of what got us all through it was just everybody just got in and just did what they did and then moved on to help somebody else... I mean we have all sort of had our day when one of us has fallen apart and yeah you sort of pick them up". 
The community-orientated focus demonstrated by individuals immediately post-Cyclone Yasi points to a high level of occupational engagement and satisfaction. People's involvement in recovery occupations seemed to provide them with meaning and purpose in the wake of the cyclone's destruction. During this phase of the recovery process there was a strong sense of hope and a desire to facilitate the return of the community to its previous state.

\section{Interruption to social, leisure and productive occupations}

As the energy, enthusiasm and altruism associated with the immediate post-impact and (early) recovery phases subsided, the impact of Cyclone Yasi began to result in a profound disruption to individuals' familiar leisure and productive occupations. Nearly two years after the cyclone, many participants were still experiencing occupational disruption within these domains.

"The social gathering places were gone... Friday nights was the country club and the pub, so there was none of that. Yeah there was just nowhere to go".

(Cathy)

Many participants described a reduced sense of pleasure garnered from leisure occupations, particularly those which were intrinsically tied to the natural environment. For example, Gabby bemoaned the loss of enjoyment that she previously had when engaging in the leisure occupations of walking and hiking.

"It was realising that this was long term and realising the level of the devastation.

That basically my life here, the things that I enjoyed, would never be the same. The reality of it was that these were 100 year old trees; I could never have what I had before. And it was later on when I realised all this more and more that I felt like running away”.

(Gabby)

Perhaps out of necessity, following the tasks of cleaning-up post-Cyclone Yasi, many participants reported they had relinquished leisure-based occupations, instead prioritising returning to employment. However, the meaning, value and sense of attachment associated with these productive occupations were also compromised due to changes resulting from the disaster. 
"Before the cyclone we employed two full-time workers, now we just employ someone part time. We just have so much more work now for me and [partner], even though the shop is quieter".

(Irene)

Some participants reported feeling exhausted and, at times, frustrated in their working and social roles due to the gradual erosion of the purpose and satisfaction that they had previously experienced through helping others.

"I think with work it has changed, not so much with the work itself, but I have so many people coming into work telling me their stories. It just starts to really get you down. Especially when you are trying to deal with your own problems it really just starts to get too much. And you can't be rude; you can't walk away or say you don't want to hear about it".

(Irene)

The ongoing disruption to everyday occupations relating to work and leisure highlight the need for individuals to adapt their relationship with these occupations in order to continue the recovery process. Participants identified a strong link between these lost occupations and the value placed on their overall lifestyle.

\section{Reconstruction: a second disaster}

The cyclone destroyed the foreshore and the main thoroughfare through the town, along which stood a majority of the shops and community services. Closure of this main road together with the redesign of the foreshore resulted in major disruption to the day-to-day occupations of the residents. Participants indicated that the foreshore redevelopment, which began 18 months after the disaster had added an additional toll on the community as they attempted to recover. They deemed the reconstruction effort to be a 'second disaster', this time man-made, rather than natural, from which another recovery process was required. It brought with it further barriers to the resumption of lost occupations, thus compounding the impact of the cyclone itself.

Participants expressed a sense that their recovery was going backwards because of the reconstruction, resulting in a decline in mood, quality of life and general well-being.

“...they have been here for what 12 months or whatever it is now and where is the progress? What has changed? It is not making anything better, it is making it worse". 
"With all the stuff pulled up and everything and the road works and everything it was no different to what it was the day after the cyclone".

(Diane)

"Like I said this [the reconstruction] is like going back to after the cyclone".

(Cathy)

Not only did the redevelopment have significant effects on individuals' recovery, but also on what the town meant as a community for those living in it.

“...they are not putting [our town] back to the way it was. It is constant change and people don't want change, they don't like it. It really is difficult... they are actually taking our beach away and to me, that's what [our town] is".

(Irene)

Some individuals refused to accept these changes, expressing a longing for their past lives and a rejection of the new normality.

\section{Occupational Liminality}

At the time of their interviews, many participants had not yet managed to transition to a sense of new normality in their valued occupations and instead seemed trapped in a state of occupational liminality. During this time, individuals were unable to accept the changes brought about by the disaster and consequently had not adapted their occupations or attempted to forge new meanings through them. For many, occupational engagement seemed to have stalled.

"I mean look at [the foreshore], almost two years later, look at it what it looks like, it's terrible. How can we move on when our town looks like that?"

(Gabby) 
"I think that it will probably be not in my lifetime actually. I won't see things return to how they were in the past... I don't think in my lifetime I will see things return to how they were in the past".

(Allan)

Individuals revealed that their bond with the township weakened following the cyclone. This loss of attachment had led some participants to reappraise why they were living in the town and begin to question whether it would be the right place for them in the future.

"At the moment, I could just pack up and walk away from [town]. It is just terrible. You do love the place so much. But you could, and maybe it is just the change you need".

(Irene)

Despite envisaging a future elsewhere, some of these participants felt trapped in the community due to the financial consequences of the disaster or personal reasons such as family ties. Thus, individuals became suspended in this liminal phase.

"I don't know if I want to stay here anymore, even though this has been my home for so long. It is different now. I have actually thought this whole thing through. I have considered leaving, but of course [my spouse] doesn't want to leave”.

(Gabby)

This theme highlights the individuality of the timing surrounding adaptation to loss and change, with some participants embracing the changes and adapting to the new opportunities. Others, meanwhile, felt suspended in a liminal phase of recovery, holding onto hope that their lives and occupations would return to what they were prior to the disaster.

\section{A new normal}

Although all participants seemed to experience a liminal phase (as described above), some managed to transition through this towards a state of 'new normal' more quickly than others. Those who did so seemed to have come to a point of acknowledgement that things could no 
longer be the same as they were prior to the cyclone, thus paving the way for previously familiar occupations to be reintegrated into their lives in new ways.

"What is normal? As normal as they are ever going to be... you don't ever forget how things were. It is always in the back of your mind. I think it is as normal as it is ever going to get”.

(Fran)

"It will never be normal as it was, it will be normal in the new way".

Fran highlighted the importance of a stable occupational routine in ensuring a sense of safety and reassurance for her children post Cyclone Yasi.

“...we tried to keep their lives as normal as possible for as long as possible.... We tried to get the kids back to school as quickly as possible so they could get their life back to normal”.

It is important to note that, while many individuals had come to recognise a new normal, it was not always welcomed. A number of participants expressed acceptance that their lives had permanently changed but, in doing so, seemed to struggle with the magnitude of their loss.

"To be honest it will be the end of [town] as we know it, well as we knew it... I think that we are going to have to learn to live in a different town".

"...he then felt like vomiting... It is like when someone dies, that is how you feel and react. And for him I guess it was the death of everything he knew and loved. He has lived here all his life".

(Gabby)

This theme highlights the value in people's establishing a sense of 'new normal' as they forge new meanings from former occupational routines. Importantly, however, adjusting to such 
significant change can be a slow and difficult process for some individuals, pointing to the potential need for support during this time.

\section{Explanatory model}

In examining the data from this study it became clear that the themes that emerged were not distinct entities, but rather interconnected facets of the participants' overall experience of occupational disruption and recovery. Based on this, an explanatory model was created depicting the influence of both natural and subsequent 'man-made' environmental changes upon participants' occupational engagement as they transitioned towards occupational recovery. (See Figure 1 below).

\section{[PLEASE ATTACH FIGURE 1 HERE]}

The model illustrates the process which individuals undergo during their recovery and how this relates to occupational engagement. The horizontal axis of the model indicates time. It is important to note that whilst all participants seemed to experience each phase of the occupational recovery process, the amount of time participants spent in each of these phases varied, depending on the individual. It is also important to note that the transition between each phase did not occur suddenly, but rather in a gradual, fluid manner and, as such, each phase is depicted on the model with permeable lines. Occupational engagement is represented along the vertical axis. Occupational engagement here does not simply represent involvement in activity for activity's sake, but rather participation in valued occupations from which individuals are able to derive a sense of meaning, purpose and belonging (Wilcock \& Hocking, 2015).

\section{Discussion:}

Literature surrounding recovery post-disaster has historically emphasised the value of returning to how things were through the re-establishment of disrupted occupations and routines (Tierney, Lindell, \& Perry, 2002). This study, however, identified some of the complexities within this process, highlighting that for occupational recovery to occur, individuals need to reorganise their understanding of themselves as occupational beings within a changed context as the "new normal". This finding is consistent with that of Wisner 
(2004) whose examination of disaster recovery found that, rather than depend on restoration, adaptation to everyday life may be required in order to recover. The theory of occupational adaptation, therefore, offers a useful framework for understanding the findings of this research. Implicit within this theory are the ideas that adaptation is a precursor to (rather than a result of) occupational performance and that the adaptive capacity of individuals is both triggered and enhanced by meaning (Schultz, 2014).

Through the lens of occupational adaptation, the fact that individuals appeared to be occupationally 'thriving' during the initial recovery phase can thus be understood as a press for mastery within an altered occupational environment. The culture of community cohesion and togetherness that emerged as individuals focussed on establishing the safety, security and immediate well-being of themselves and those around them appeared to nurture (temporarily at least) a sense of hope and feelings of mastery over their personal recovery as well as the recovery of the town. The sense of meaning during this phase seemed centred on a shared sense of community and on a belief that the environmental changes were temporary in nature and that the township could soon be restored to its former state. This finding resonates with previous literature which identified a tendency towards altruistic behaviour as communities come together to rebuild what was lost in the immediate aftermath of a natural disaster (Bates \& Peacock, 1987; De Los Milagros et al., 2015; Miller, 2007; Morrow \& Peacock, (1997)). This points to the potential for the social capital established during this time to be leveraged, so as to maintain an ongoing sense of community connectedness, thus fostering the conditions needed for ongoing occupational engagement during the long recovery process. In doing so, the longer-term occupational disruption experienced through either loss or changes to social, leisure and employment opportunities might be mitigated.

The difficulties participants experienced in coming to terms with what they perceived to be the 'second disaster' (in the form of the reconstruction) can be understood as resulting from the loss of control (mastery) and meaning resulting from the changes occurring during this period of time (Schultz, 2014). The demands associated with the constancy and duration of the environmental disruption, coupled with an emerging recognition of the permanency of change, seemed to exceed the adaptive capacity of many participants. This contributed to a sense of compassion fatigue during the reconstruction phase, as the purpose and satisfaction that many participants had previously garnered through helping others now left them feeling exhausted and frustrated. Previous literature surrounding compassion fatigue post-disaster has pointed to its presence among workers and volunteers (Figley, 2002). This study reveals that 
survivors can experience compassion fatigue during times when their own adaptive response to change has been compromised and their everyday occupations (such as working in the retail sector) regularly expose them to people who have also undergone the traumatic event.

The finding that participants entered into a period of occupational liminality when they transitioned from a phase of occupational disruption towards the establishment of a 'new normal' offers a new perspective on the challenges associated with the recovery process. Liminality (from the Latin Limen, or threshold) has been defined as a state of being 'betwixt and between' and describes a transitional period of life where individuals are 'at the threshold' but not yet fully re-established in the social order (Turner, 1974; van Gennep, 1909/1960). Liminality is characterised by a sense of ambiguity and disorientation where individuals are unable to engage in their traditional or usual occupations and have yet to make the necessary adaptations to a new situation (Turner, 1974). Within this research, occupational liminality appeared to result in a state of limbo in which individuals were waiting for former occupations to return, rather than adapting these occupations and their meanings or seeking new occupations. For many, this phase seemed particularly hard to cope with, as they had lost their perception of belonging to the town as it used to be, but had not yet forged a new sense of occupational identity and connectedness with the world in which they now lived, thereby compromising their ability to adapt to change.

Following the phase of occupational liminality, a final state of occupational recovery had occurred for some (but not all) participants. In this stage of the recovery process, participants had managed to forge new meanings within their occupational routines and thus establish a new sense of normality. It should be noted that this did not necessarily entail the abandonment of the old memories and meanings associated with the township. Instead, those individuals who had arrived at a 'new normal', had managed to maintain a sense of enduring connectedness to the town that they loved whilst at the same time developing new meanings in their lives post-disaster. This finding resonates strongly with the core principles underpinning occupational adaptation theory, through the recognition of the critical role that valued occupations play in shaping an individual's personal sense of identity, meaning and purpose in relation to the dynamic, evolving world in which they live (Schultz, 2014). Service providers assisting disaster survivors would be well positioned to assist individuals who find themselves 'stuck' in a state of occupational liminality by supporting them to shape 
a renewed understanding of themselves as occupational beings within a changed environment.

\section{Limitations:}

A number of limitations are present in this research. The research team limited the study to one particular township and included a requirement for study participants to have lived in the [regional town] for 10 years or more. This was intended to exclude the perspectives of transient populations of seasonal workers and tourists who often reside in the town for part of any given year. This may, however, have had a compromising effect on maximum variation sampling. The study was also undertaken at one specific time period (two years after the cyclone) at which time the reconstruction was still not complete. This point of focus offers very useful information about people's thoughts and experiences during what is often a very lengthy reconstruction phase. However, it is likely that many participants' perspectives on their experience of occupational disruption and occupational recovery may have altered somewhat, had the reconstruction been finalised. Research in which this community perceptions are revisited, now that the reconstruction is complete, would add an interesting dimension to the findings presented in this study.

\section{Conclusion:}

To date, there has been a paucity of literature comprehensively examining the occupational implications of disaster and the barriers and further disruptions which may occur during the recovery process. This study found that, in the wake of a natural disaster, individuals experienced a phased process of occupational recovery. Directly after the event individuals were occupationally thriving as they engaged in recovery occupations; however, when these came to an end, varying degrees of occupational disruption arose. The meanings and enjoyment individuals placed on their occupations were later further disrupted by a second 'man-made disaster", resulting from the reconstruction work within the town. As this period of occupational disruption continued, some individuals became entrenched within a phase of occupational liminality, in which they seemed unable to recognise the permanency of the changes to their occupational context. Individuals who had emerged from this phase of occupational liminality had managed to derive new meaning from and enjoyment within their 
occupational routines, thereby establishing a sense of 'new normal'. The findings of this research offer insights into the experience of occupational disruption and the subsequent process of occupational adaptation that occurs through the gradual establishment of new meanings within the changed environmental context. In doing so, they shed light on the importance of efforts to support the occupational adaptation among individuals and communities as part of the long-term response to a natural disaster, so as to promote best outcomes during a period of tumultuous change. 


\section{Reference List}

AOTA. (2011). The role of occupational therapy in disaster preparedness, response, and recovery. AJOT: American Journal of Occupational Therapy, 65(6), S11. doi:10.5014/ajot.2011.65S11

Bates, F. L., \& Peacock, W. G. (1987). Disaster and social change. In R. Dynes, B. DeMarchi, \& C. Pelanda (Eds.), Sociology of disaster: contribution of sociology to disaster research. (pp. 291330). Milan: Franco Angeli.

Britten, N. (1995). Qualitative Interviews In Medical Research. BMJ: British Medical Journal, 311(6999), 251-253.

Caruana, C. (2010). Picking up the pieces : family functioning in the aftermath of natural disaster. Family Matters, 84(84), 79-88.

Colorafi, K. J., \& Evans, B. (2016). Qualitative descriptive methods in health science research. Health Environments Research \& Design Journal, 9(4), 16-25. doi:10.1177/1937586715614171

Corbin Dwyer, S., \& Buckle, J. (2009). The Space Between: On Being an Insider-Outsider in Qualitative Research. International Journal of Qualitative Methods, 8(1), 54-63. doi:10.1177/160940690900800105

Creswell, J. W. (2013). Qualitative inquiry and research design: choosing among five approaches (Vol. 3rd). Thousand Oaks, Calif: SAGE Publications.

De Los Milagros, D. M., Boggio, C., Boffelli, M., Chiapessoni, D., Demichells, M., \& del Carmen Heit, M. (2015). Listening to the voices of survivors: The flood of 2003 in Sante Fe, Argentina. In N. Rushford \& K. Thomas (Eds.), Disaster and development: an occupational perspective (pp. 53-62). Edinburgh: Elsevier.

Figley, C. R. (2002). Treating compassion fatigue. London;New York, N.Y;: Brunner-Routledge.

Guha-Sapir, D., Vos, F., \& Below, R. (2011). Annual disaster statistical review 2011. Brussels, Belgium: Centre for Research on Epidemiology of Disasters (CRED)

Jeong, Y., Law, M., DeMatteo, C., Stratford, P., \& Kim, H. (2016). The role of occupational therapists in the contexts of a natural disaster: a scoping review. Disability \& Rehabilitation, 38(16), 1620-1631. doi:10.3109/09638288.2015.1106597

Kanuha, V. K. (2000). Being" Native versus "Going Native": Conducting Social Work Research as an Insider. Social Work, 45(5), 439-447. doi:10.1093/sw/45.5.439

Lee, H. C. (2014). The role of occupational therapy in the recovery stage of disaster relief: A report from earthquake stricken areas in China. Australian Occupational Therapy Journal, 61(1), 28-31. doi:10.1111/1440-1630.12106

McColl, M. A. (2002). Occupation in stressful times. American Journal of Occupational Therapy, 56(3), 350-353.

Miller, L. M. (2007). Collective responses to Karina and Rita: Exploring therapeutic community, social capital and social control. . Southern Rural Sociology, 22, 45-63.

Morrow, B. H., \& Peacock, W. G. ((1997)). Disasters and social change: Hurricance Andrew and the reshaping of Miami. In W. G. Peacock, B. H. Morrow, \& H. Gladwin (Eds.), Hurricane Andrew: Ethnicity, gender and the sociology of disasters. (pp. 226-242). London: Routledge.

Pizzi, M. A. (2015). Hurricane Sandy, Disaster Preparedness, and the Recovery Model. American Journal of Occupational Therapy, 69(4), 6904250010p6904250011. doi:10.5014/ajot.2015.015990

Rosenfeld, M. S. (1982). A model for activity intervention in disaster-stricken communities. The American journal of occupational therapy : official publication of the American Occupational Therapy Association, 36(4), 229.

Rushford, N., \& Thomas, K. (2015). Disaster and development: an occupational perspective. Edinburgh: Elsevier.

Sandelowski, M. (2010). What's in a name? Qualitative description revisited. Research in Nursing and Health, 33(1), 77-84. doi:10.1002/nur.20362

Schultz, S. W. (2014). Theory of occupational adaptation. In H. S. Willard \& B. A. B. Schell (Eds.), Willard \& Spackman's occupational therapy (Vol. 12th, pp. 527-540). Philadelphia: Wolters Kluwer Health/Lippincott Williams \& Wilkins. 
Smith, T. M., \& Scaffa, M. E. (2014). Providing occupational therapy for disaster survivors. In B. A. Boyt Schell, G. Gillen, M. E. Scaffa, \& E. Cohn (Eds.), Willard \& Spackman's occupational therapy (12th ed., Vol. 12th, pp. 962-971). Philadelphia: Wolters Kluwer Health/Lippincott Williams \& Wilkins.

Taylor, E., Jacobs, R., \& Marsh, E. D. (2011). First Year Post-Katrina: Changes in Occupational Performance and Emotional Responses. Occupational Therapy in Mental Health, 27(1), 3-25. doi:10.1080/0164212X.2011.543454

Tierney, K. J., Lindell, M. K., \& Perry, R. W. (2002). Facing the Unexpected: Disaster Preparedness and Response in the United States. Disaster Prevention and Management: An International Journal, 11(3), 222-222. doi:10.1108/dpm.2002.11.3.222.1

Townsend, E. A., \& Polatajko, H. J. (2013). (Vol. Second). Ottawa, Ontario: Canadian Association of Occupational Therapists.

Turner, V. (1974). Dramas, fields and metaphors: Symbolic action in human society. New York.: Cornell University Press.

van Gennep, A. (1909/1960). The rites of passage. Chicago: University of Chicago Press.

Van Manen, M. (1990). Researching Lived Experience: Human Science for an Action Sensitive Pedagogy. Albany: State University of New York Press.

Whiteford, G. (2010). Occupational deprivation: understanding limited participation. In C. Christiansen \& E. A. Townsend (Eds.), Introduction to occupation: the art and science of living. (Vol. 2nd, pp. 303-328). Upper Saddle River, N.J: Pearson.

Wilcock, A. A., \& Hocking, C. (2015). An occupational perspective of health (Vol. Third). Thorofare, NJ: SLACK Incorporated.

Wisner, B. (2004). At risk: natural hazards, people's vulnerability, and disasters (Vol. 2nd). New York, NY: Routledge. 


\section{Attachments}

Table 1

\begin{tabular}{|l|l|l|l|}
\hline Pseudonym & Age Bracket* & Gender & Occupation \\
\hline Allan & $55-64$ & Male & Real estate agent \\
\hline Beth & $55-64$ & Female & Retired, Animal Carer \\
\hline Cathy & $45-54$ & Female & Retail \\
\hline Diane & $35-44$ & Female & Retail \\
\hline Eric & $55-64$ & Male & Building and construction \\
\hline Fran & $35-44$ & Female & Garden maintenance \\
\hline Gabby & $45-54$ & Female & Mother and business administration \\
\hline Hugh & $45-54$ & Male & Fisherman \\
\hline Irene & $45-54$ & Female & Retail \\
\hline
\end{tabular}

* Age depicted in ranges to maintain anonymity. 
Figure 1: Explanatory Model

MODEL OF OCCUPATIONAL DISRUPTION AND RECOVERY FOLLOWING NATURAL DISASTER

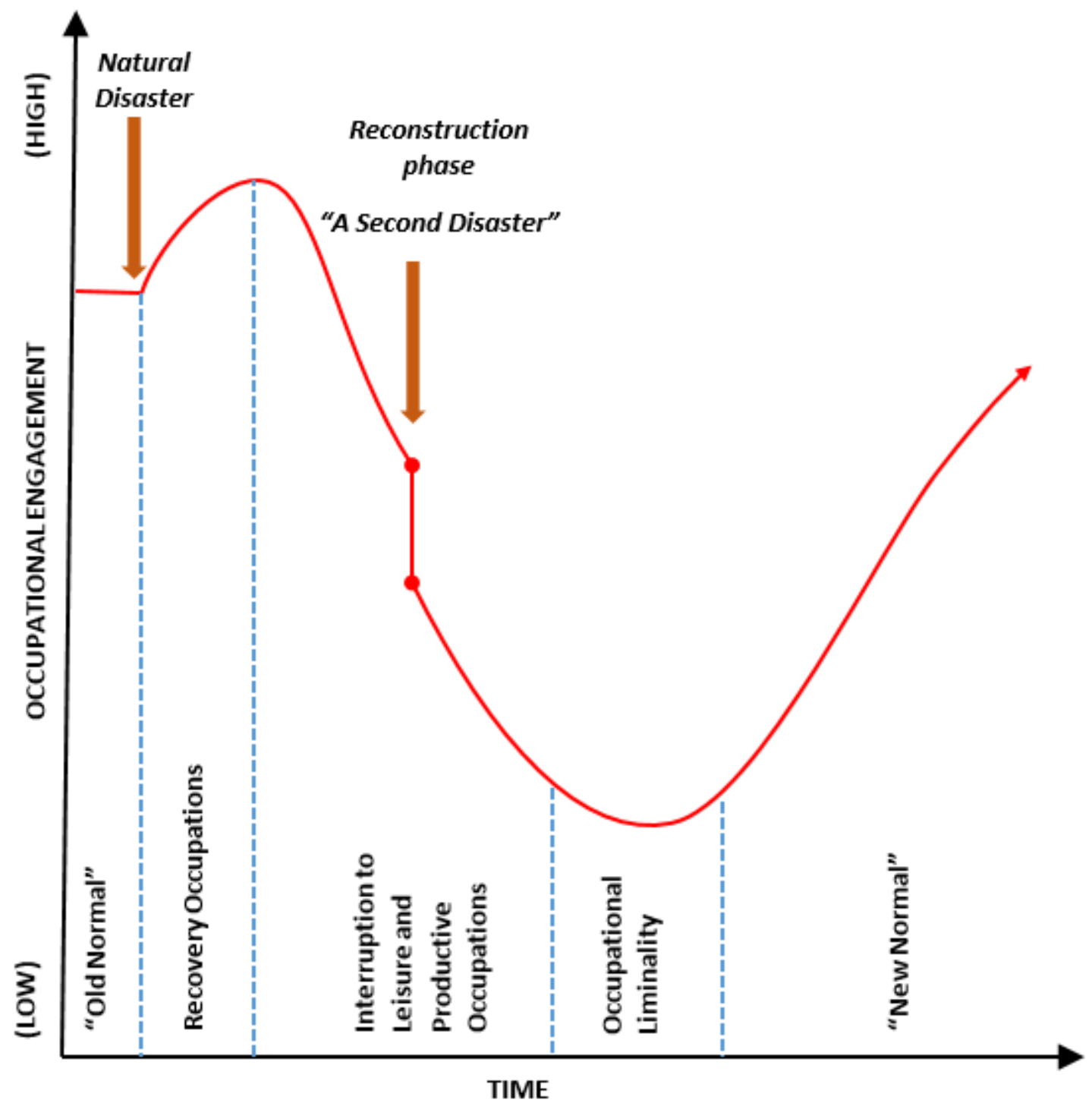




\section{Appendix 1: Interview Questions (and prompts)}

\section{Background Questions}

- How long have you lived in [regional town]?

- Were you at home leading up to Cyclone Yasi?

- Did you evacuate during Cyclone Yasi? If not, why did you choose to stay?

- How long after Cyclone Yasi did you come home?

- Who do you currently live with? Has this changed since the Cyclone?

- What was it like coming back home after Cyclone Yasi? How did you feel?

- Was your home or workplace damaged, what about the township generally?

\section{Changes in Roles, Habits and Routines}

- What was your day-to-day routine before Cyclone Yasi?

- What roles did you have before Cyclone Yasi?

- What type of work were you involved in before Cyclone Yasi?

- What leisure activities did you do before Cyclone Yasi?

- How has your day-to-day life changed since Cyclone Yasi?

- What were the most significant changes that you had to confront immediately after the cyclone?

- What were things like in the immediate aftermath?

- Have things that you did on a regular basis changed since Cyclone Yasi?

- Have your leisure activities, work, household duties changed since Cyclone Yasi?

- How has your lifestyle changed since Cyclone Yasi?

- Do you think anything has changed permanently for you, or are changes only temporary?

Recovery Process Questions 
- Do you feel that things have returned to 'normal' since the cyclone?

- What (if anything) is the same?

$\circ \quad$ How have things changed?

- How far along the recovery process do you think you are?

- What are the barriers to your recovery?

$\circ$ What is helping your recovery?

$\circ$ Are there any points in time during your recovery process that have been particularly significant to you?

- What do you feel has helped you the most through this time?

- What changes would you still like to see?

$\underline{\text { Additional }}$

- Are there any other thoughts or comments on this topic that you would like to share? 